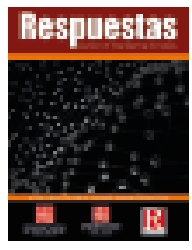

Original Article
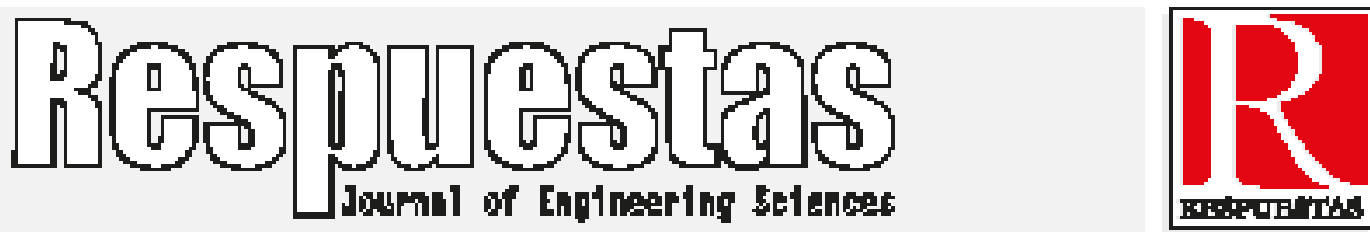

\title{
Liquid balance - steam for methanol mixing - Benzen using the Peng Robinson and Van-Laar models
}

Balance de líquidos - vapor para mezcla de metanol - Benzen usando los modelos Peng Robinson y VanLaar

Miguel Fernando Palencia-Muñoz ${ }^{1}$ Natalia Prieto-Jiménez², Germán González-Silva ${ }^{3 *}$

${ }^{\prime}$ Magister en Ingeniería de Hidrocarburos, mfpalencia@hotmail.com, ORCID 0000-0002-7623-1038, Universidad Industrial de Santander, Bucaramanga, Colombia.

${ }^{2}$ Candidata a Doctor en Ingeniería Quimica, natispj@gmail.com, ORCID 0000-0001-9178-7758, Universidad Industrial de Santander, Bucaramanga, Colombia.

3*Doctor en Ingeniería Química, germangs@uis.edu.co, ORCID 0000-0002-4642-1092, Universidad Industrial de Santander, Bucaramanga, Colombia.

How to cite: M. Palencia-Muñoz, N. Prieto-Jiménez y G. González-Silva, "Liquid balance - steam for methanol mixing Benzen using the Peng Robinson and Van-Laar models”. Respuestas, vol. 24, no. 1, pp. 34-41, 2019.

Received on April 30, 2018; Approved on September 7, 2018

\begin{tabular}{ll}
\hline & ABSTRACT \\
\hline Keywords: & $\begin{array}{l}\text { This paper is related to the procedure for calculating curves dew point and bubble point of a } \\
\text { binary system, consisting of the methanol and benzene mixture to } 45^{\circ} \mathrm{C} \text {, using the Peng-Robinson } \\
\text { cubic equation to calculate the fugacity coefficient of gas i in the mixture, and Van Laar model to } \\
\text { calculate the activity coefficient of component i in the liquid mixture. Then a comparison between }\end{array}$ \\
Azeotrope & $\begin{array}{l}\text { the theoretical data with the experimental data and later with the commercial simulator Hysys- } \\
\text { Activity coefficient } \\
\text { Aspen, which applies the model of Wilson. The simulation was validated with experimental data, } \\
\text { in addition to comparing the results with a commercial simulator. }\end{array}$
\end{tabular}

\section{RESUMEN}

Palabras clave:

Azeótropo

Coeficiente de actividad

Coeficiente de fugacidad

Equilibrio vapor-líquido
El presente artículo está relacionado con el procedimiento para obtener las curvas de punto de rocío y de punto de burbuja en un equilibrio líquido - vapor (VLE) para una mezcla binaria con azeótropo de Metanol y Benceno a $45^{\circ} \mathrm{C}$, utilizando la ecuación cúbica de Peng Robinson para calcular el coeficiente de fugacidad del gas i en la mezcla gaseosa, y el modelo de Van Laar para calcular el coeficiente de actividad del componente $i$ en la mezcla líquida. Luego se compararon los datos teóricos con datos experimentales, posteriormente con el simulador comercial, el cual aplica el modelo de Wilson, se logró validar los datos experimentales, además de comparar los resultados con un simulador comercial.

\section{Introduction}

Studies on the equilibrium of the mixing phase are of considerable importance for the design of thermal separation processes and theoretical understanding of molecular behavior [1]. Oxygenated compounds such as methyl tert-butyl ether (MTBE), ethyl tertbutyl ether (ETBE) and methyl tert-amyl ether (TAME) can be used as gasoline additives due to their good anti-knocking properties, VLE data of these additives with alcohols and hydrocarbons are used to develop calculation models for the reformulation of gasoline Jong-Hyeok et al [2], [3] determined isothermal experimental results of liquid-vapor equilibrium for five binary substances among them the mixture methanol and benzene. In the last decade there has been a growing demand for the use of oxygenated compounds to produce unleaded gasoline [4] - [7]. Gramajo de Doz et al [8] analyzed the equilibrium phases of the systems 
containing hydrocarbons (benzene, isooctane, toluene, or cyclohexane) and oxygenated compounds (methanol, ethanol, or methyl tert-butyl ether), due to the physical and chemical properties of methanol, as a candidate for an oxygenated fuel additive. However, methanol has partial miscibility with aliphatic hydrocarbons, but not with aromatic hydrocarbons. Therefore, it is of great importance to study systems composed of methanol and hydrocarbon components representative of gasoline. In 2013 García et al [9], focused on studying the diagrams of hydrocarbon phases such as gasoline and methanol through tertiary and quaternary systems, (heptane + benzene + methanol), (heptane + ethylbenzene + methanol), (heptane + m-xylene + methanol), (heptane + benzene + ethylbenzene + methanol), and (heptane + Benzene + m-xylene + methanol) at temperature of $293.15 \mathrm{~K}$ and atmospheric pressure, to define the solubility of methanol in gasoline at low temperatures. The mixture of these components is not only used for fuel alcohol additives, it has also been used as a raw material for the synthesis of other chemicals and polymers; accurate data on the phase equilibrium of mixtures of propylene oxide with hydrocarbons (methanol-benzene) are necessary for proper design and optimization of the relevant chemical processes and purification steps [10]. Subsequently, these components have been analyzed with the purpose of making an efficient and adequate selection of a solvent for the separation of azeotropes with methanol, which is why ionic liquids (ILS) have received significant interest in recent years as its application in industrial processes refers [11]. In recent years, new applications have been found for methanol derivatives such as gasoline additives, biofuels, diesel fuels etc., because mixtures of this with other substances have proven to be effective and non-toxic inhibitors of ice formation. [12].

\section{Materials and methods}

Initially to calculate this curve the study temperature must be defined, for this case it is $45^{\circ} \mathrm{C}$, the compositions of the liquid phase are assumed and all $\Phi \mathrm{i}$ is set equal to one, which will be used to calculate an estimated value of the pressure of the system as initial data; the critical properties of each component and acentric factor $(\square)$ are determined, which were taken from the book by Reid et al [13] and are summarized in Table 1.

Table I. Critical properties of the pure components Methanol and Benzene

\begin{tabular}{|c|c|c|c|c|c|}
\hline & $\begin{array}{c}\mathrm{Tc} \\
{[\mathrm{K}]}\end{array}$ & $\begin{array}{c}\mathrm{Pc} \\
{[\mathrm{KPa}]}\end{array}$ & $\begin{array}{c}\mathrm{Vc} \\
{\left[\mathrm{m}^{3} . \mathrm{Kmol}-1\right]}\end{array}$ & $\mathrm{Zc}$ & ๘ \\
\hline Methanol & 512.6 & 8090 & 0.118 & 0.22 & 0.56 \\
\hline Benzene & 562.2 & 4890 & 0.259 & 0.27 & 0.21 \\
\hline
\end{tabular}

The procedure to calculate the bubble point curve, part of the liquid-vapor equilibrium equation at low pressures:

$$
\mathrm{P} y_{i} \Phi_{i}=x_{i} \gamma_{i} P_{i}^{s a t}
$$

First step (Bubble Point): The saturation pressure of each component is calculated at a temperature of $45^{\circ} \mathrm{C}$ using the Antoine equation for base logarithm 10 , where the temperature units for equation number 2 are in degrees Celsius and the units of pressure are Torr, which is subsequently converted to $\mathrm{KPa}$ by multiplying by the factor 0.133322 . The Antoine coefficients for each component are found in Table II.

$$
\log \left(P_{i}^{s a t}\right)=A-\frac{B}{\left(T^{\circ}+C\right)}
$$

Table II. Antoine constants (A, B, C)

\begin{tabular}{|c|c|c|c|}
\hline & A & B & C \\
\hline Methanol & 8.08097 & 1582.271 & 239.726 \\
\hline Benzene & 6.87987 & 1196.76 & 219.161 \\
\hline
\end{tabular}

Second step (Bubble Point): The activity coefficients are calculated using the Van Laar model at the temperature and composition of the given liquid phase, the constants for the Methanol-Benzene mixture at $45^{\circ} \mathrm{C}$ are $\mathrm{A}_{12}=2.1623$ and $\mathrm{A}_{21}=1.7925$. 


$$
\begin{aligned}
& \ln \left(\gamma_{1}\right)=A_{12}\left(\frac{A_{21} x_{2}}{A_{12} x_{1}+A_{21} x_{2}}\right)^{2} \\
& \ln \left(\gamma_{2}\right)=A_{21}\left(\frac{A_{12} x_{1}}{A_{12} x_{1}+A_{21} x_{2}}\right)^{2}
\end{aligned}
$$

Third step (Bubble Point): The initial system pressure at temperature and established liquid phase compositions is calculated assuming a $\Phi_{\mathrm{i}}$ equal to one, using the following expression:

$$
\mathrm{P}=\sum \frac{x_{i} \gamma_{i} P_{i}^{\text {sat }}}{\Phi_{i}}
$$

Fourth step (Bubble Point): Steam fractions are calculated by clearing $\mathrm{y}_{\mathrm{i}}$ from equation number 1 , the following expression is obtained from this process:

$$
y_{i}=\frac{x_{i} \gamma_{i} P_{i}^{s a t}}{\mathrm{P} \Phi_{i}}
$$

Fifth step (Bubble Point): With the vapor fractions, the transience coefficients for Methanol and Benzene are calculated using equation number 7 and the cubic state equation of Peng Robinson:

$$
\Phi_{i}=\frac{\widehat{\varphi}_{l}}{\varphi_{i}^{\text {sat }}} \exp \left[\frac{-v_{i}^{L}\left(P-P_{i}^{\text {sat }}\right)}{R T}\right]
$$

Using Peng-Robinson to calculate the transience coefficient requires several calculations:

$$
\begin{gathered}
\alpha=\left[1+\left(\begin{array}{c}
0.37464+1.54226 w \\
\left.-0.26992 w^{2}\right)(1 \\
\left.\left.-\operatorname{Tr}^{0.5}\right)\right]^{2}
\end{array}\right.\right. \\
a=\frac{0.45724 R^{2} T c^{2}}{P c} \alpha \\
b=\frac{0.0778 R T C}{P c}
\end{gathered}
$$

Polynomial shape:

$$
\begin{gathered}
A=\frac{a P}{R^{2} T^{2}} \\
B=\frac{b P}{R T} \\
Z^{3}-(1-B) Z^{2}+\left(A-3 B^{2}-2 B\right) Z-\cdots \\
\ldots-\left(A B-B^{2}-B^{3}\right)=0
\end{gathered}
$$

Mixing rules:

$$
\begin{gathered}
a_{i j}=\sqrt{a_{i} a_{j}}\left(1-k_{i j}\right) \\
a=\sum \sum Y_{i} Y_{j} a_{i j} \\
b=\sum Y_{i} b_{i}
\end{gathered}
$$

Fugue coefficients for components in solution:

$$
\begin{gathered}
\ln \widehat{\varphi}_{\iota}=\frac{b_{i}}{b}(z-1)-\ln (z-B)+\frac{A}{B 2 \sqrt{2}} . . \\
\ldots\left(\frac{b_{i}}{b}-\sigma_{i}\right) \ln \frac{z+B(1+\sqrt{2)}}{z+B(1-\sqrt{2)}} \\
\sigma_{i}=2\left(\frac{a_{i}}{a}\right)
\end{gathered}
$$

The fugacity coefficient equation for pure substances is applied to find the $\varphi \mathrm{i}^{\wedge}$ sat of each component of the mixture, recalculating equations 11,12 and 13 , with the saturation pressure and using them in the following expression:

$$
\begin{gathered}
\ln \Phi_{i}=(z-1)-\ln (z-B)-\frac{A}{2 \sqrt{2 B}} . \\
\ldots \ln \frac{z+2.414 B}{z-0.414 B}
\end{gathered}
$$

Sixth step (Bubble Point): The system pressure is recalculated with equation number 5 using the calculated $\Phi$ i of each component in the previous step, this procedure or iteration is performed several times until the difference between the initially defined system pressure and the system pressure recalculated 
with the $\Phi$ i new, be less than the tolerance $\varepsilon=0.01$ established.

$$
\Delta P=\operatorname{abs}\left(P_{\text {initially }}-P_{\text {System }}\right)<\varepsilon
$$

After the above condition is met, the bubble pressure curve is constructed by plotting $\mathrm{P}$ system vs $\mathrm{X}_{\mathrm{i}}$.

\section{Calculation of the dew point curve}

To find this curve, several of the algebraic expressions written above were used, but the procedure varied somewhat with respect to the process explained in section 2. In the first step, the vapor phase compositions are assumed, the saturation pressure is calculated with the Antoine equation, equation number 2 ; it is assumed $\Phi_{\mathrm{i}}=1$ for the first evaluation of the iterative process and in the same way the $\gamma_{i}=1$ (since they cannot be calculated and depend on the composition of the liquid phase). With the data and parameters established above, the initial dew pressure of the system is calculated.

$$
\mathrm{P}=\frac{1}{\sum \frac{y_{i} \Phi_{i}}{\gamma_{i} P_{i}^{s a t}}}
$$

Second step (Dew Point): With the estimated initial system pressure, the compositions of the liquid phase are determined, rearranging equation number 1 .

$$
x_{i}=\frac{y_{i} \mathrm{P} \Phi_{i}}{\gamma_{i} P_{i}^{\text {sat }}}
$$

Third step (Dew Point): With the determined liquid fractions the activity coefficients are calculated $\gamma_{\text {inicially }}$ using the Van Laar model expressed in equations number 3 and 4 .

Fourth step (Dew Point): System pressure is recalculated $\mathrm{P}_{\text {Sist2 }}$ using equation number 21 with the initial $\gamma_{\text {initially }}$ calculated in the previous step

Fifth step (Dew Point): Фi is determined for each component using the expressions given from equation number 7 to number 19 .
Sixth step (Dew Point): With the parameters obtained in steps three, four and five the fractions of the liquid phase are recalculated using equation number 22 and they are normalized. With the normalized $X_{i}$ the activity coefficients are recalculated again $\gamma_{\text {recalculated }}$ for the Van Laar model with equations number 3 and 4.

Seventh step (Dew Point): The $\gamma_{\mathrm{i}}$ delta is evaluated to be less than the tolerance $\varepsilon=0.01$. If this is not fulfilled, the fractions of the liquid phase with the last phase are calculated $\gamma_{\text {recalculated }}$, the $X_{i}$ are normalized and the activity coefficient is recalculated to find the new $\gamma_{\text {recalcula }}$, this procedure is performed until condition $\Delta \gamma_{i}<\varepsilon$ is met.

$$
\Delta \gamma_{i}=a b s\left(\gamma_{\text {initially }}-\gamma_{\text {recalculated }}\right)<\varepsilon
$$

Eighth step (Dew Point): Finally with the $\gamma_{\text {recalculated }}$ the final system pressure is calculated $\mathrm{P}_{\text {Sist3 }}$ with equation 21 and it is evaluated that $\Delta \mathrm{P}$ is less than the tolerance $\varepsilon=0.01$.

$$
\Delta P=\operatorname{abs}\left(P_{\text {Sist } 2}-P_{\text {Sist } 3}\right)<\varepsilon
$$

If the previous condition is not satisfied, the whole process is performed again but using $\gamma_{\text {recalculado }}$ to determine the system pressure $\mathrm{P}_{\text {Sist2 }}$ and recalculate all parameters, the iterations will continue until the condition $\Delta \mathrm{P}<\varepsilon$ is met. Then the dew pressure curve is constructed by graphing $\mathrm{P}_{\mathrm{Sist3}}$ vs $\mathrm{Y}_{\mathrm{i}}$.

\section{Results and Discussion}

\section{Comparison between the peng Robinson-Van Laar model theoretically calculated, experimental data and simulation in hysys-aspen de la mix}

The procedures described in numeral 2 and 3 were the basis of the algorithm for programming the Matlab code and obtaining the dew point and bubble point curves using the Peng Robinson - Van Laar model to calculate the transience coefficients and the coefficients of activity of the binary mixture 
Methanol-Benzene at $45^{\circ} \mathrm{C}$, the calculated data can be seen in Figure 1 and Table III.

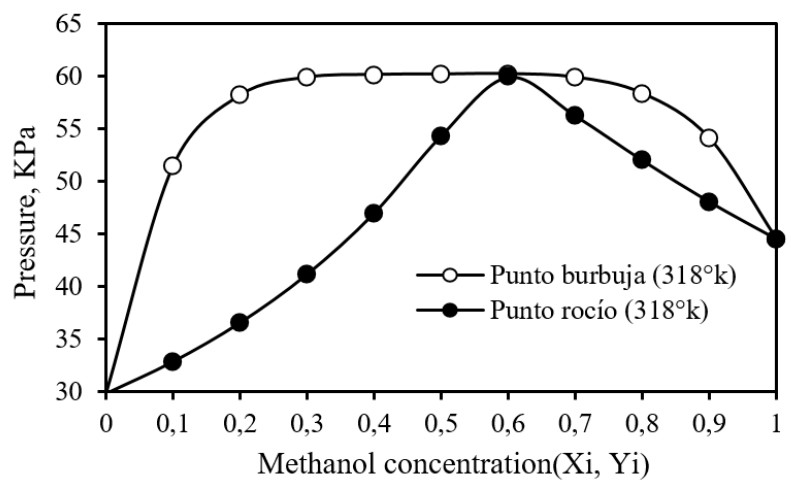

Figure 1. P-X-Y diagram for the Methanol-Benzene mixture at $45^{\circ} \mathrm{C}\left(318.15^{\circ} \mathrm{K}\right)$

To verify the validity of the theoretically calculated data with the Matlab algorithm, a simulation of the liquid-vapor balance of the mixture was performed using the "Hysys-Aspen" program with the Wilson model to the conditions of the case study, the results are shown in Table 4, a comparison was also made with the experimental data of the Methanol-Benzene mixture that he used as a model of transience, the Redlich-Kwong equation, and for the liquid phase he uses the Wilson activity model the results are summarized in Table 5, both models were selected for their degree of reliability for the analyzed system. The comparative graphs $(\mathrm{P}-\mathrm{X}-\mathrm{Y})$ of the $45^{\circ}$ Methanol Benzene mixture with the three models mentioned are shown in Figures 2, 3 and 4.

Table III. Theoretical data calculated for the VLE Isotherm at $45^{\circ} \mathrm{C}$ for the Methanol-Benzene mixture

\begin{tabular}{|c|c|c|c|}
\hline \multicolumn{2}{|c|}{ Bubble Curve } & \multicolumn{2}{c|}{ Dew Curve } \\
\hline $\mathrm{P}_{\mathrm{b}}[\mathrm{KPa}]$ & $\mathrm{X}_{1}$ & $\mathrm{P}_{\mathrm{r}}[\mathrm{KPa}]$ & $\mathrm{Y}_{1}$ \\
\hline 29.799 & 0 & 29.799 & 0 \\
\hline 51.425 & 0.1 & 32.841 & 0.1 \\
\hline 58.162 & 0.2 & 36.551 & 0.2 \\
\hline 59.871 & 0.3 & 41.158 & 0.3 \\
\hline 60.137 & 0.4 & 46.975 & 0.4 \\
\hline 60.177 & 0.5 & 54.331 & 0.5 \\
\hline 60.208 & 0.6 & 59.921 & 0.6 \\
\hline 59.885 & 0.7 & 56.252 & 0.7 \\
\hline 58.355 & 0.8 & 52.013 & 0.8 \\
\hline 54.092 & 0.9 & 48.058 & 0.9 \\
\hline 44.523 & 1 & 44.523 & 1 \\
\hline
\end{tabular}

The theoretically calculated data were subjected to analysis with the data of the other models used to verify the validity of the algorithm and its results; The standard deviation of the theoretical calculations with respect to the other models were $(0.146$ theoretical vs. experimental), (theoretical 0.0974 vs. simulation program).

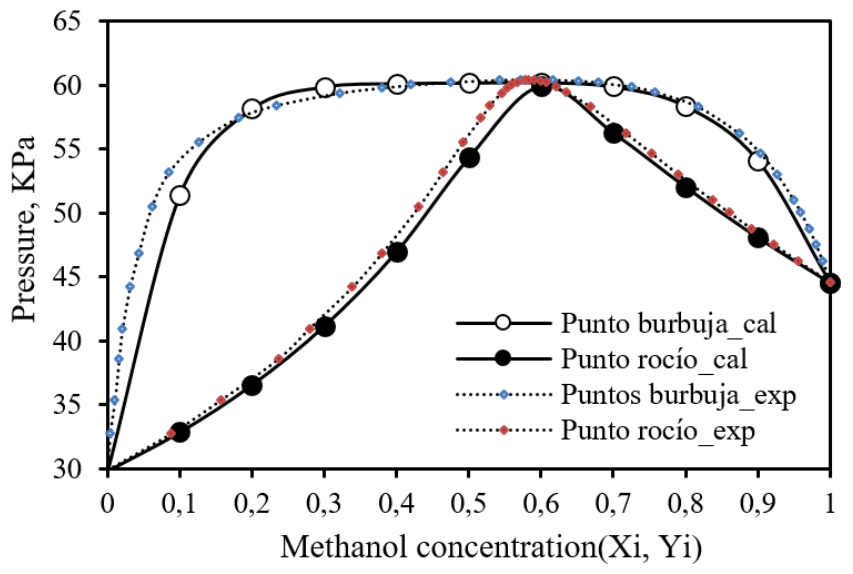

Figure 2. $\mathrm{P}-\mathrm{X}-\mathrm{Y}$ diagram for the mixture Methanol - Benzene at $45^{\circ} \mathrm{C}$, comparison between theoretically calculated data and experimental data of Marian Góral et al (2004)

Figure 2 shows that the theoretical curve of the bubble and dew points is slightly out of phase with respect to the experimental values, a result that was expected due to the standard deviation previously analyzed between these two curves, however the algorithm used to obtaining these theoretical data can be useful as an approximation to analyze the behavior of these curves at different temperatures.

Table IV. Data calculated with Hysys-Aspen simulator for the MethanolBenzene mixture at $45^{\circ} \mathrm{C}$. Applying the Wilson model

\begin{tabular}{|c|c|c|}
\hline FER] & $x_{1}$ & $\mathbf{Y}_{1}$ \\
\hline 29.72411 & 0 & D \\
\hline 41.014:: & 0.034aix? & 020000 \\
\hline 47.41003 & 0.04065 & $0.40 \mathrm{mes}$ \\
\hline 51.45206 & 0.1034483 & 0.4632511 \\
\hline s4017a & D.17gal & 0.4964 \\
\hline 55.735: & 0.1724138 & 0signor \\
\hline 569394 & 960 & 216 \\
\hline 57.7954 & 0.2415993 & $0 \leq 44444$ \\
\hline 5:42496 & axsines & $0 \leq 55600$ \\
\hline s:aroue & 03103448 & 0503093 \\
\hline Sp254az & 0344756 & oseptul \\
\hline
\end{tabular}




\begin{tabular}{|c|c|c|}
\hline 5954913 & a 3793103 & $0 \leq 750016$ \\
\hline s9.7794 & 0.4137931 & 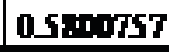 \\
\hline S9g5es1 & 0.442359 & \\
\hline Dongraz & a.tiens: & 0 S \\
\hline EDzolas & 05172414 & 0 \\
\hline ED27/24 & 0551724 & 05 \\
\hline 003201 & a siocong & 0.8 \\
\hline $00325+$ & a.6osigr & 0.0 \\
\hline EDzin & 0.6551724 & 0.6 \\
\hline D.103a & 0.6:20552 & 0.5 \\
\hline 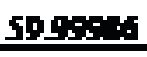 & 379 & \\
\hline $59.705 \%$ & 0.75:007 & 0.64450 \\
\hline Spzs:" & 0.7931034 & 0.65.1118 \\
\hline SFSTSAR & arepsian & 0.675:-1 \\
\hline 57.5 .17 & D.enges & 0.09858 \\
\hline 5604755 & ario6517 & 0.731 .2 \\
\hline 53.74102 & 09310345 & 0.7.13:0 \\
\hline 50.1750 & abs5172 & 0.759R41 \\
\hline 1.4896 & 1 & 1 \\
\hline
\end{tabular}

The data simulated with "Hysys-Aspen" recorded in Table 4, show a similar behavior to the experimental data in Table V, which is why at some points the curves overlap; the standard deviation between these two curves was 0.0654 , this behavior infers that the simulator data can be reliable to adjust and calibrate the theoretical model calculated with Peng-Robinson and Van Laar used in the Matlab algorithm.

Table V. Experimental data for the vapor-liquid equilibrium of the MethanolBenzene mixture at $45^{\circ} \mathrm{C}$, from Góral et al (2004)

\begin{tabular}{|c|c|c|}
\hline PIKP] & $x_{1}$ & $\mathbf{Y}_{\mathbf{1}}$ \\
\hline 29.804 & 0 & 0 \\
\hline 3274 & 0.0077 & D.0112 \\
\hline 35.3교 & 0.0102 & D.1587 \\
\hline 189787 & 0.0181 & 0.2364 \\
\hline 40.9.8. & 0.0007 & 0274 \\
\hline 44.231 & 0.0314 & D.3791 \\
\hline $46 \times 32$ & 0.0431 & 0.774 \\
\hline 50.458 & 0.0613 & D.4306 \\
\hline 53.224 & $0.0: 54$ & D.4542 \\
\hline 55.57 & 0.129 & D.4821 \\
\hline 57.454 & 0.1211 & Dsith \\
\hline
\end{tabular}

\begin{tabular}{|c|c|c|}
\hline S8:427 & 02334 & Dsats \\
\hline $5.4 m$ & 03217 & 0545 \\
\hline s.s.m & 0 stos & DSst: \\
\hline Co.DIs & 0.4201 & 0.589 \\
\hline 60242 & 0.4745 & DSST3 \\
\hline 0.416 & 0542 & DSTlu \\
\hline 60.443 & 05716 & Dsal \\
\hline 60.416 & 0.6154 & Dseot \\
\hline 6035 & 0.6509 & $0 \times 9$ \\
\hline c0.215 & 0.0799 & D.e0s7 \\
\hline \$P.8. & 0.725 & D.sel6 \\
\hline$\$ 9.452$ & 0.7575 & D.8456 \\
\hline S8.321 & osln & D.soll \\
\hline 56213 & 0.744 & D.7nl \\
\hline 54.022 & 0.0030 & D.7S25 \\
\hline 33.037 & 0.0864 & D.756 \\
\hline 51.009 & ogyt & D.1358 \\
\hline 50.048 & 0.0594 & D. 1509 \\
\hline 48767 & ogrot & D.sis \\
\hline 4754 & ogato4 & 09202 \\
\hline 46272 & ogass & Dosst \\
\hline 44.cos & ] & $\mathbf{1}$ \\
\hline
\end{tabular}

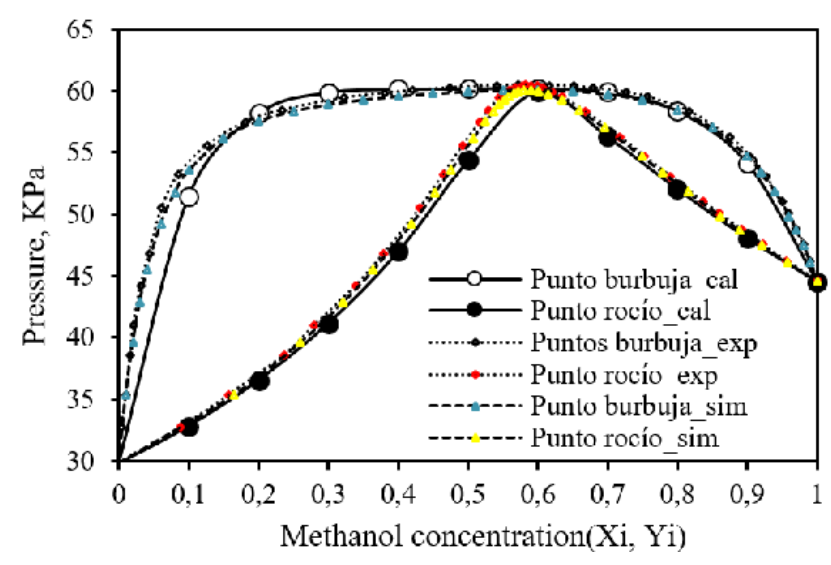

Figure 3. P-X-Y diagram for the Methanol - Benzene mixture at $45^{\circ} \mathrm{C}$, with experimental data, data theoretically calculated by the algorithm and simulated with "Hysys-Aspen"

In Figure 3 a comparison of the experimental and simulated data is made with the theoretical data calculated by the algorithm designed for this article following the procedure explained in numeral 2 and 3 ; all the aforementioned analyzes are consolidated and the similarity between the experimental data and those simulated by "Hysys-Aspen" in which the standard deviation analyzed was 0.0654 between these two curves is clearly observed. 
A similar behavior is observed in Figure 3, the theoretical data are outdated with respect to the results shown by the simulator, but in this case the standard deviation was 0.0974 which is slightly smaller than that observed in the curves of Figure 2.

\section{Conclusions}

The theoretical model proposed in the algorithm made for this article using the Peng Robinson cubic equation to calculate the transience coefficient and the Van Laar model to determine the activity coefficient, can be used as an approximate method to determine the point curves of dew and bubble point of a binary mixture at low pressures. After analyzing the theoretical calculations thrown by the Matlab algorithm, with the experimental and simulator data respectively, it is observed that the standard deviation of the program is between 0.0974 and 0.146 at the points farthest from the curves, this error may be associated with the tolerance used during programming. The standard deviation obtained from the analysis of the curves between experimental and simulator data was 0.0654 , so the reliability of the simulator data can be inferred to adjust and calibrate the theoretical model calculated with Peng-Robinson and Van Laar used in the Matlab algorithm.

\section{Acknowledgments}

We thank Colciencias, the Seed Capital for Research, Project with code 2370 and seedbed in nanotechnology, modeling and numerical simulation applied to the oil industry, code 5482 of the Vice-Rectory for Research and Extension of the Universidad Industrial de Santander.

\section{References}

[1] N. Prieto Jiménez y G. González Silva, «Comparative Study of Equations of State for the Dew Curves Calculation in High Pressure Natural Gas Mixtures.», Rev. Logos Cienc. Tecnol., vol. 11, n.o 1, p. 13, 2018.

[2] J.-H. Oh, K.-J. Han, D.-B. Won, y S.-J. Park, «Vapor-liquid equilibria for the ternary systems of methyl tert-butyl ether+ methanol+ benzene and methyl tert-butyl ether+ methanol+ toluene and constituent binary systems at $313.15 \mathrm{~K} »$, Fluid Phase Equilibria, vol. 209, n.o 2, pp. 215-228, 2003.

[3] J.-H. Oh y S.-J. Park, «Vapor- liquid equilibria for the ternary systems of methyl tert-butyl ether+ methanol+ methylcyclohexane and methyl tert-butyl ether+ methanol+ n-heptane and constituent binary systems at $313.15 \mathrm{~K} », J$. Chem. Eng. Data, vol. 50, n.o 5, pp. 1564-1569, 2005.

[4] M. K. Balki y C. Sayin, «The effect of compression ratio on the performance, emissions and combustion of an SI (spark ignition) engine fueled with pure ethanol, methanol and unleaded gasoline», Energy, vol. 71, pp. 194-201, 2014.

[5] L. Wen, C.-Y. Xin, y S.-C. Yang, «The effect of adding dimethyl carbonate $(\mathrm{DMC})$ and ethanol to unleaded gasoline on exhaust emission», Appl. Energy, vol. 87, n.o 1, pp. 115$121,2010$.

[6] M. Eyidogan, A. N. Ozsezen, M. Canakci, y A. Turkcan, «Impact of alcohol-gasoline fuel blends on the performance and combustion characteristics of an SI engine», Fuel, vol. 89, n.o 10, pp. 2713-2720, 2010.

[7] P. Iodice, G. Langella, y A. Amoresano, «Ethanol in gasoline fuel blends: Effect on fuel consumption and engine out emissions of SI engines in cold operating conditions», Appl. Therm. Eng., vol. 130, pp. 1081-1089, 2018.

[8] M. B. Gramajo y A. M. Cases, «Liquid-Liquid Equilibria of the Methanol+ Hexane+ Methylcyclohexane+ Toluene Quaternary System at T=303.15 K», J. Solut. Chem., vol. 44, n.o 2, pp. 171-180, 2015.

[9] B. E. García-Flores, J. Águila-Hernández, F. GarcíaSánchez, y M. A. Aquino-Olivos, «(Liquid-liquid) equilibria for ternary and quaternary systems of representative compounds of gasoline+ methanol at $293.15 \mathrm{~K}$ : Experimental data and correlation», Fluid Phase Equilibria, vol. 348, pp. 60-69, 2013.

[10] P. M. Mathias, Guidelines for the Analysis of Vapor-Liquid Equilibrium Data. ACS Publications, 2017.

[11] F. Cai et al., «Isobaric vapor-liquid equilibrium for methanol+ dimethyl carbonate + phosphoric-based ionic liquids», Fluid Phase Equilibria, vol. 352, pp. 47-53, 2013.

[12] M. Yakovleva, E. Vorobyov, I. Pukinsky, I. Prikhodko, G. Kuranov, y N. Smirnova, «Liquid-liquid equilibria for ternary mixtures of 2, 2-dimethyl-1, 3-dioxolane-4-methanol with n-heptane, toluene, ethanol and water», Fluid Phase Equilibria, vol. 405, pp. 107-113, 2015. 
[13] B. E. Poling, J. M. Prausnitz, y J. O. Connell, The

Properties of Gases and Liquids, 5.a ed. New York: McGrawHill Professional, 2000. 